Comunicaçāo. Validade do conceito de forma indeterminada da doença de chagas. (I Reuniāo de Pesquisa Aplicada em Doença de Chagas). Revista da Sociedade Brasileira de Medicina Tropical 18: 46, Jan-Mar, 1985.

\title{
VALIDADE DO CONCEITO DE FORMA INDETERMINADA DE DOENÇA DE CHAGAS
}

Considerando as controvérsias havidas sobre a validade do conceito da chamada forma indeterminada da doença de Chagas, inclusive com repercussões desfavoráveis para o paciente do ponto de vista médico, social e trabalhista, os participantes da I Reunião de Pesquisa Aplicada em Doença de Chagas realizada em Araxá (MG), no periodo de 13 a $15 / 12 / 1984$, resolveram referendar os seguintes parâmetros para caracterizá-la:

1. Positividade de exames sorológicos e/ou parasitológicos;

2. Ausência de sintomas e/ou sinais da doença;
3. Eletrocardiograma convencional normal;

4. Coração, esôfago e colons radiologicamente normais.

Consideram ainda conveniente a manutenção deste conceito de forma indeterminada para avaliação clínica e estudos epidemiológicos tendo em vista o bom prognóstico dos casos.

Finalmente, enfatizam que em chagásicos incluidos nos critérios acima expostos quando submetidos a exames mais sensiveis podem ser observadas alterações o que, entretanto, não invalida o conceito aqui expresso. 